Fiona Crawford, NH, Phil Hanlon, Jill Muirie, and DO, who all contributed equally to the thinking that inspired this article.

Funding: None.

Competing interests: None declared.

1 Obesity: preventing and managing the global epidemic. Report of a WHO consultation. World Health Organization Technical Report Series 2000;894:1-253.

2 Storing up problems: the medical case for a slimmer nation. London: Royal College of Physicians of London, Royal College of Paediatrics and Child College of Physicians of London, Royal Coll
Health, and Faculty of Public Health, 2004.

Health, and Faculty of Public Health, 2004.
Egger G, Swinburn B. An "ecological" approach to the obesity pandemic. BMJ 1997;315:477-80.

Department of Health. Choosing health:making healthier choices easier. London: Stationery Office, 2004

5 Asp N-G, Björntorp P, Britton M, Carlsson P, Kjellström T, Marcus C, et al. Obesity - problems and interventions. Stockholm: Statens beredning för medicinsk utvärdering (The Swedish Council on Technology Assessment in Health Care), 2002.

6 Ebbeling C, Pawlak D, Ludwig D. Childhood obesity: public-health crisis, common sense cure. Lancet 2002;360:473-82.

7 Department for Transport. Transport statistics bulletin:national travel survey Department for Transport. Transport statisti
2002. London: Stationery Office, 2004.
8 Peters J, Wyatt H, Donahoo W, Hill J. From instinct to intellect: the challenge of maintaining healthy weight in the modern world. Obes Rev 2009.3.69-74

9 Swinburn B, Egger G. The runaway weight gain train: too many accelerators, not enough brakes. BMJ 2004;329:736-9.

10 Day J. Scottish schools ban food adverts. Guardian 2003;24 Dec http://media.guardian.co.uk/advertising/story/0,1112620,00.html (accessed 27 Jan 2004).

11 Neroth P. Fat of the land. Lancet 2004;364:651-3.

12 World Health Organization. Diet, nutrition and the prevention of chromic diseases. Report of a joint WHO/FAO expert consultation. Geneva: WHO, 2003.

13 Cable News Network. Transcript of President Bush's address to a joint session of Congress on Thursday night, Sept 20, 2001. http:// www.cnn.com/2001/US/09/20/gen.bush.transcript (accessed 27 Jan www.c

14 Hamilton C. Growth fetish. London: Pluto, 2004

15 Department for Transport. It's no joke. www.cyclesense.net (accessed 10 Jun 2005).

16 Lean M. Prognosis in obesity. BMJ 2005;330:1339-40.

17 Ellaway A, Macintyre S. "5-a-day" may be harder to achieve in more deprived areas. J Epidemiol Community Health 2004;58:892.

18 Ellaway A, Macintyre S. Play areas for children. J Epidemiol Communit Health 2003;57:315.

(Accepted 14 October 2005)

\title{
What is successful ageing and who should define it?
}

\author{
Ann Bowling, Paul Dieppe \\ A definition of successful ageing needs to include elements that matter to elderly people
}

Department of Primary Care and Population

Sciences, University College London, London NW3 2PF

Ann Bowling professor of health services research

Medical Research Council Health Services Research Collaboration,

Department of Social Medicine, University of Bristol, Bristol BS8 2PR

Paul Dieppe

director

Correspondence to: A Bowling a.bowling@ucl.ac.uk

BMJ 2005;331:1548-51

\section{Methods}

We discuss existing models of the constituents of successful ageing from the social, psychological, and medical sciences. We undertook a systematic literature review, searching PubMed, PsycINFO, and SocioFile (all years) for "successful ageing." We included 170 papers presenting reviews or overviews of the topic, data from cross sectional and longitudinal surveys, and qualitative studies (full list available on request, but the main ones are listed here $\left.{ }^{2-22}\right)$. We also included lay definitions elicited from our own recent survey of successful ageing.

\section{What is successful ageing?}

The main themes emerging from the theoretical literature reflected psychosocial or biomedical approaches, or combinations of these (see box). There was some

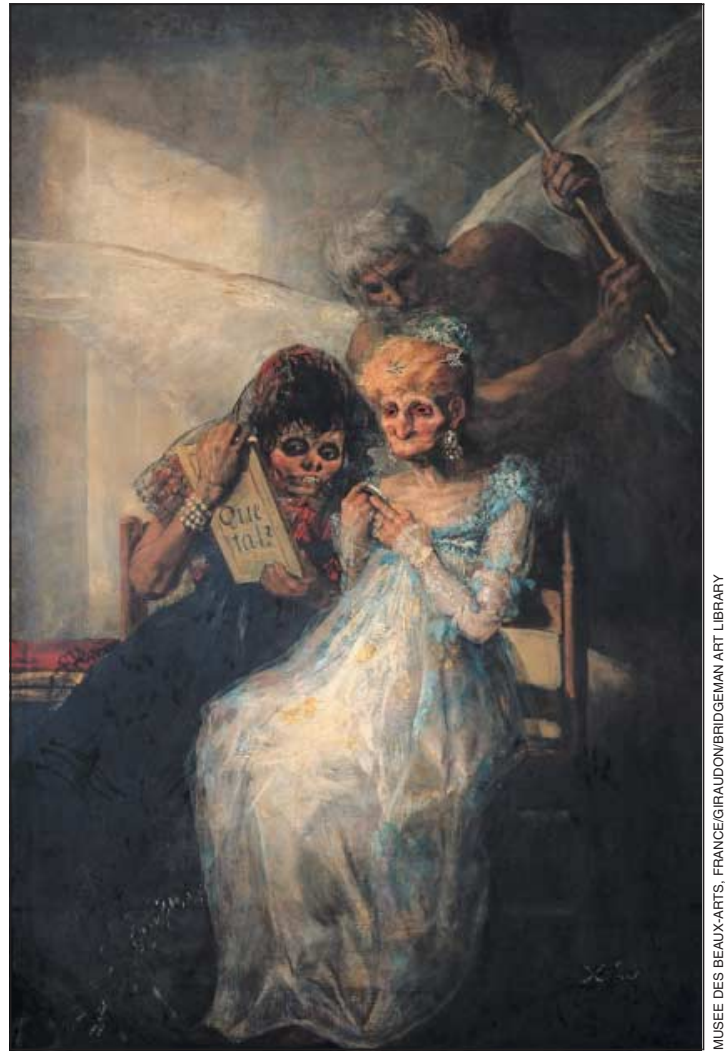

Decline and fall? Goya's Les Vieilles ("Time of the Old Women")

overlap with lay views; although the latter were more comprehensive and multidimensional.

\section{Biomedical theories}

Biomedical theories define successful ageing largely in terms of the optimisation of life expectancy while minimising physical and mental deterioration and disability. They focus on: the absence of chronic disease and of risk 
factors for disease; good health; and high levels of independent physical functioning, performance, mobility, and cognitive functioning. The MacArthur studies of successful ageing, based on a three site longitudinal study of elderly US adults living in the community in $1988,{ }^{3}{ }^{8}$ are the most well known and widely published biomedical studies of successful ageing.

The division of people into "diseased" and "normal" fails to recognise the large heterogeneity within these groups. To overcome this, Rowe and Kahn distinguished between "usual ageing" (normal decline in physical, social, and cognitive functioning with age, heightened by extrinsic factors) and "successful ageing" in which functional loss is minimised (little or no age related decrement in physiological and cognitive functioning, with extrinsic factors playing a neutral or positive role). ${ }^{3}$ They confirmed the three components of successful ageing as absence or avoidance of disease and risk factors for disease, maintenance of physical and cognitive functioning, and active engagement with life (including maintenance of autonomy and social support). Some investigators have broadened the model to include more psychosocial elements, ${ }^{4}$ although attempts to build interdisciplinary models are still rare.

Rowe and Kahn's model is the most widely used approach, but it fails to address the implications of the fact that a disease-free older age is unrealistic for most people. Moreover, it has been reported that, although half of elderly people can be categorised as having aged successfully in terms of their own criteria, fewer than a fifth can be so categorised with this traditional medical model. ${ }^{9}$

\section{Psychosocial approaches}

While the biomedical model emphasises absence of disease and the maintenance of physical and mental

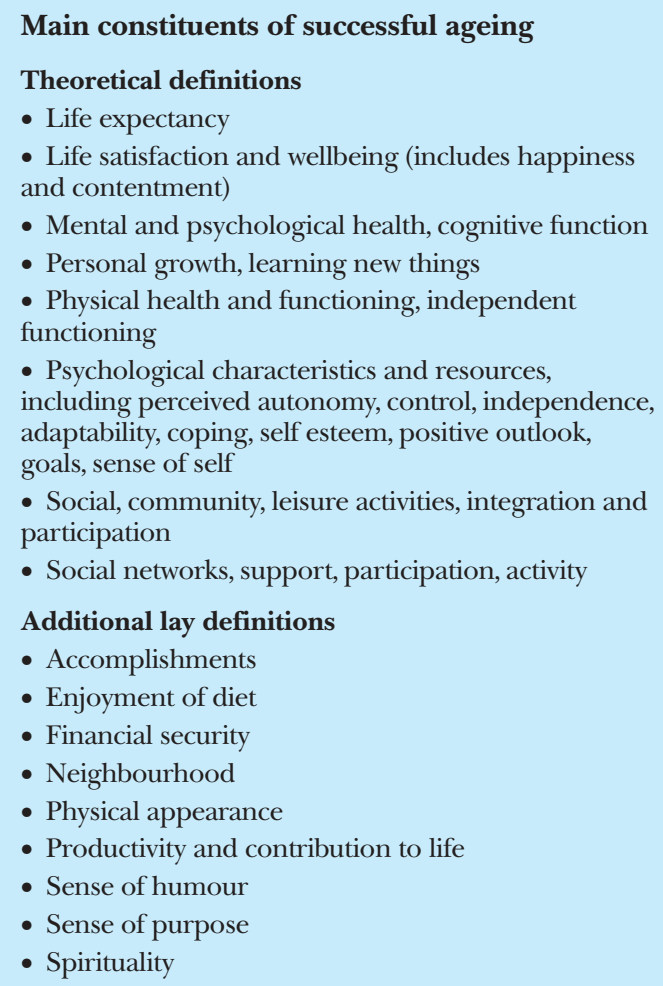

functioning as the keys to ageing successfully, sociopsychological models emphasise life satisfaction, social participation and functioning, and psychological resources, including personal growth.

Satisfaction with one's past and present life has been the most commonly proposed definition of successful ageing, and is also the most commonly investigated..$^{15}$ Its components include zest, resolution and fortitude, happiness, relationships between desired and achieved goals, self concept, morale, mood, and overall wellbeing. Continued social functioning is another commonly proposed domain of successful ageing. It encompasses high levels of ability in social role functioning, positive interactions or relationships with others, social integration, and reciprocal participation in society. ${ }^{16}$

Suggested psychological resources for successful ageing include a positive outlook and self worth, self efficacy or sense of control over life, autonomy and independence, and effective coping and adaptive strategies in the face of changing circumstances. For example, when some activities are curtailed (say, because of ill health) strategies need to be activated to find new activities and to maximise one's reserves. ${ }^{17}$ Successful ageing is seen as a dynamic process, as the outcome of one's development over the life course, ${ }^{18}$ and as the ability to grow and learn by using past experiences to cope with present circumstances while maintaining a realistic sense of self.

\section{Lay views}

There are a few investigations into older people's views of what is successful ageing. ${ }^{19}$ Their definitions include mental, psychological, physical, and social health; functioning and resources; life satisfaction; having a sense of purpose; financial security; learning new things; accomplishments; physical appearance; productivity; contribution to life; sense of humour; and spirituality. The box lists several lay definitions that are not captured adequately by theoretical models.

We also conducted a national, random population survey of perceptions of successful ageing among 854 people aged 50 or more, living at home in Britain; this was part of an Office for National Statistics omnibus survey (analyses ongoing). Of these people, 75\% (631) rated themselves as ageing successfully "Very well" or "Well" (as opposed to "Alright," "Not well" or "Not very well"). The most commonly mentioned definition of successful ageing, in response to open ended questioning, was having good health and functioning, but these were rarely mentioned in isolation, and most people mentioned more than one definition (see figure). Typical comments were:

"[Successful ageing is to] go out a lot and enjoy life, take it day by day, and enjoy what you can ... Have good health-that's more important than anything else. Keep active-while your legs are moving get out on them."

"[It's] good health. Well, if you're fit and able to do more ... active ... you ... contribute to society and get actively involved."

"It's your outlook on life to start with. I think I have been an active person. It's your whole outlook. Do you make an effort to keep fit? I don't think about getting old. I just don't feel old and act accordingly." 


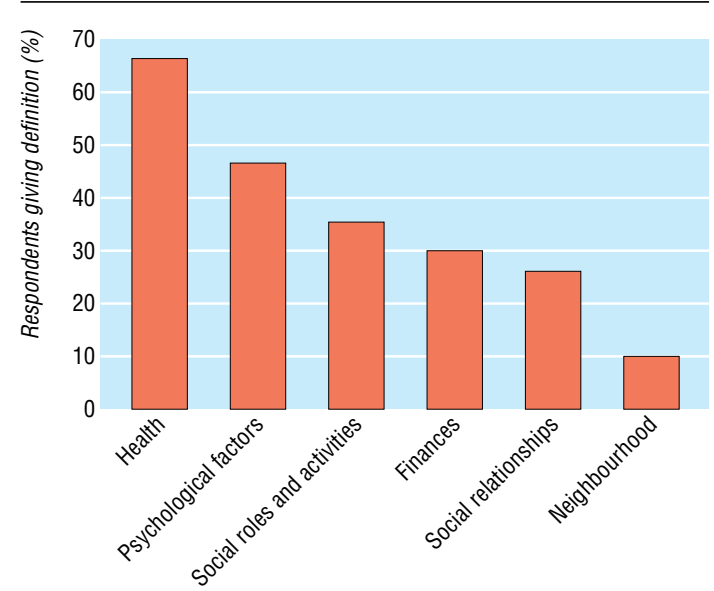

Most common definitions of successful ageing given by 854 people aged $\geq 50$ in Britain

Less commonly, successful ageing was defined in terms of social capital, as retiring in a safe neighbourhood, and with good community facilities.

\section{Policy implications}

Several policy implications become evident from a broader interpretation of the concept of successful ageing. Biomedical research has developed to include the investigation of biological pathways to unsuccessful ageing (impaired mental and physical functioning, including immunological and genetic markers), although the current policy focus is on disease prevention and health promotion for achieving successful ageing. Most behavioural actions for successful ageing continue to promote health related behaviours and engagement in cognitively stimulating activities. Indeed, on the basis of the Landmark Harvard study of adult development, Vaillant argued that successful ageing is less dependent upon genetic predisposition than previously thought. ${ }^{4}$

If high social functioning, for example, is accepted as part of ageing successfully, the implication is that people need encouragement to build up their social activities and networks from a young age, and the provision of enabling community facilities is needed. This is given impetus by research indicating that many domains of successful ageing are inter-related, and that having multiple social activities and relationships is associated with life satisfaction and better health and functioning, autonomy, and survival. ${ }^{40}$

Psychosocial models have also culminated in the positive psychology movement, with its proponents of the benefits of learnt optimism. ${ }^{23}$ It has been postulated that people can learn to see "a bottle half full" instead of "a bottle half empty" and that having a happy outlook is a skill that can be cultivated. But, irrespective of the likelihood of genetic influences, getting people to "cheer up" is not always easy in real life.

With greater recognition that older people are not a homogeneous group, health professionals need more balanced, interdisciplinary perspectives of older age. People's low expectations of ageing are associated with their placing less importance on seeking health care. ${ }^{21}$ Clinicians need to be aware of their patients' val- ues and expectations of ageing in order to enhance mutual understanding of their health goals and priorities, ${ }^{19}$ and to consider interventions that will optimise their chances of "ageing successfully" in their terms. However, interventions need to target potentially vulnerable groups early on, as several longitudinal datasets have shown that variables measured in middle age predict outcomes in old age. ${ }^{4}$ Consistent with this are longitudinal data showing that adaptation to old age is related to experiences of stressful events, and is also associated with social class. ${ }^{24}$

\section{Conclusions}

Most concepts of successful ageing are used uncritically and tend to reflect the academic discipline of the investigator. Many authors have also confused constituents with precursors. While the biomedical models emphasised absence of disease and good physical and mental functioning as successful ageing, sociopsychological models emphasised life satisfaction, social functioning and participation, or psychological resources. Lay views of successful ageing are important for testing the validity of existing models and measures, if they are to have any relevance to the population they are applied to. There is little point in developing policy goals if elderly people do not regard them as relevant.

Most health care provided in the developed world goes to those aged 65 years or above. The medical model is so dominant that few health professionals are aware of psychosocial ageing. The result is a focus on the burden of old age, the decline and failure of the body. This negative perspective inevitably dominates consultations between doctors and patients. However, there is ample evidence that many elderly people regard themselves as happy and well, even in the presence of disease or disability. Doctors should be aware that many elderly people consider themselves to have aged successfully, whereas classifications based on traditional medical models do not. This review led us to a paper by Callahan et al, ${ }^{22}$ who suggested that we need to examine our assumptions and adopt humility of perspective. Health professionals need to respect the values and attitudes of each elderly person who asks for help, rather than imposing our medical model on to their lives.

In conclusion, the achievement of successful ageing in terms of all the criteria presented here is unrealistic for most people. But successful ageing needs to be viewed, not only multidimensionally, but as an ideal state to be aimed for, and the concept itself should be placed on a continuum of achievement rather than subject to simplistic normative assessments of success or failure. Given the enormous body of ongoing research on the topic, it would be unhelpful to abandon the term altogether; the adoption of a broader perspective will have relevance for elderly people themselves.

We thank Sandra Short, Ian O'Sullivan and the Office for National Statistics (ONS) staff who carried out the original Omnibus Survey data analysis and collection. They hold no responsibility for the further analysis and interpretation of them. Material from the ONS Omnibus Survey, made available through ONS, has been used with the permission of the controller of the Stationery Office. The dataset will be held on the data archive at the University of Essex. 
Contributors: $\mathrm{AB}$ undertook the systematic review and analyses and is guarantor for the study. AB and PD wrote this article collaboratively.

Funding: None.

Competing interests: None declared.

Ethical approval: Not required.

1 Mor V. The compression of morbidity hypothesis: a review of research and prospects for the future. J Am Geriatr Soc 2005;53:S308-9.

2 Baltes PB, Mayer KV, eds. The Berlin ageing study. Cambridge: Cambridge University Press, 1999

Rowe JW, Kahn RL. Successful aging. New York: Pantheon Books, 1998.

4 Vaillant GE. Aging well: surprising guideposts to a happier life from the Landmark Harvard study of adult development. Boston: Little Brown, 2002.

Roos NP, Havens B. Predictors of successful aging: a twelve year study of Manitoba elderly. Am J Public Health 1991;81:63-8.

6 Crosnoe R, Elder GH. Successful adaptation in the later years: a life course approach to aging. Soc Psychol Q 2002;65:309-28.

7 An tudinal study of aging: applying the MacArthur model cross-nationally. J tudinal study of aging: ap Issues 2002;58:749-65.

8 Seeman TE, Charpentier PA, Berkman LF, Tinetti ME, Guralnik JM, Albert M, et al. Predicting changes in physical performance in a high-functioning elderly cohort. MacArthur studies of successful aging. $J$ Gerontol 1994;49:M97-108.

9 Strawbridge WJ, Wallhagen MI, Cohen RD. Successful aging and well-being. Self-rated compared with Rowe and Kahn. Gerontologist 2002;42:727-33.

10 Vaillant GE, Mukamal K. Successful aging. Am J Psychiatry 2001;158: 839-47.
11 Von Faber M. Successful aging in the oldest old: who can be characterised as successfully aged? Arch Intern Med 2001:161:2694-700.

12 Grundy E, Bowling A. Enhancing the quality of extended life years. Identification of the oldest old with a very good and very poor quality of life. Aging Ment Health 1999;3:199-212.

13 Palmore E. Predictors of successful aging. Gerontologist 1979;19:427-31.

14 Williams RH, Wirths CG. Lives through the years: styles of life and successful aging. New York: Atherton Press, 1965.

15 Havighurst RJ. Successful aging. In: Williams RH, Tibbits C, Donahue W, eds. Processes of aging. New York: Atherton Press, 1963:299-320.

16 Havighurst RL, Neugarten B, Tobin SS. Disengagement and patterns of aging. In: Neugarten BL, ed. Middle age and aging: a reader in social psycholaging. In: Neugarten BL, ed. Middle age and aging: a reader

17 Baltes PB, Baltes MM. Successful aging: perspectives from the behavioral Baltes PB, Baltes MM. Successful aging: perspectives

18 Ryff CD. Beyond Ponce de Leon and life satisfaction: new directions in quest of successful aging. Int J Behav Dev 1989;12:35-55.

19 Phelan EA, Anderson LA, Lacroix AZ, Larson EB. Older adults' views of "successful aging"-how do they compare with researchers' definitions? $J$ Am Geriatr Soc 2004;52:211-6.

$20 \mathrm{Menec} \mathrm{VH}$. The relation between everyday activities and successful aging: a 6-year longitudinal study.J Gerontol B Psychol Sci Soc Sci 2003;58:S74-82

21 Sarkisian CA, Hays RD, Mangione CM. Do older adults expect to age successfully? The associations between expectations regarding aging and beliefs regarding healthcare seeking among older adults. J Am Geriatr Soc 2002:50: 1837-43.

22 Callahan CM, McHorney CA, Mulrow CD. Successful aging and the humility of perspective. Ann Intern Med 2003;139:389-90.

23 Seligman M. Authentic happiness: using the new potential for lasting fulfilment. New York: Free Press, 2004.

24 Caspi A, Elden GH. Life satisfaction in old age: linking social psychology and history. Psychol Aging 1986;1:18-26.

(Accepted 9 October 2005)

\section{Slow tracking for BMJ papers}

\section{Christopher Martyn}

An editor argues against the current enthusiasm for fast tracking pages

It seems that it all started with the Lancet. ${ }^{1}$ In 1997 it offered to publish selected manuscripts within four weeks of submission. They claimed that their motive was to get important data into the public health arena as quickly as possible, citing worrying (worrying!) instances that they and other journals had experienced of "delays in the publication of important data with major public-health messages." Each week's delay, they asserted, is "another week during which the research findings can leak out, perhaps in distorted form, via the mass media. Without the full paper, those health-care workers who advise the public are not privy to the caveats and interpretations made by the authors of the study."

Convinced? Well, JAMA was, and a year or two later it offered much the same thing. ${ }^{2}$ It dubbed the process EXPRESS (Expedited Peer Review and Editorial System for Science) presumably to give the impression that it was JAMA's idea in the first place. Any number of other journals tagged along, and authors can now request fast track from the International Journal of Social Psychiatry, Neuropsychological Rehabilitation, the European Journal of Developmental Psychology, the Journal of Molecular Endocrinology, and the Journal of Occupational and Environmental Medicine, to name but a few. There was even a time when the Quarterly Journal of Medicine offered to fast track papers.

The BMJ has always been doubtful. As an editorial in 1999 pointed out: "It usually takes years to do a study and then years for change to happen: why rush around to reduce the time to publication by months?" But, in the end, we came around, signalling our half heartedness with the obscure-we reckoned ironicicon of a bike with oval wheels. At least we were honest about the reasons: "We hope it will attract researchers with high quality studies to submit them to the $B M J$, and we hope it will serve readers by helping us to attract better papers."

Evolutionary biologists will understand what's going on here. ${ }^{4}$ In a complex and changing system, a species needs to continue to develop just to maintain its fitness relative to other species. If a mutation allows antelopes to run faster, cheetahs must evolve or starve. But it's not only in arms races between predators and prey that this principle operates. It also happens when there is competition for limited resources. Trees in a forest compete for sunlight. If one tree grows taller, it captures sunlight that would otherwise have reached neighbouring trees. They are then forced to grow taller to avoid being overshadowed. Overall, the effect of competition is that trees become taller. But note the downside: there's still the same amount of sunlight. It's just that trees have to work harder to get their share.

It's the same with journals. To prosper they must attract the best papers-a limited resource. If one journal makes itself more attractive to authors by speeding up its processes, others are constrained to follow. But the process engenders no increase in the number of good papers. Who benefits? Certainly not the journals-they've had to expend more editorial energy on publishing the same number of papers. The authors? Probably not, because the best papers were usually published fairly promptly anyway. Readers? Again, and for the same reason, probably not. It's hard

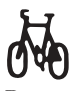

Because the author was so slow in delivering his manuscript, it had to be fast tracked to get into this issue

$B M J$, London WC1H 9JR Christopher Martyn associate editor cmartyn@bmj.com BMJ 2005;331:1551-2 